\title{
Reguetón en Cuba: censura, ostentación y grietas en las políticas mediáticas
}

\section{Simone Luci Pereira ${ }^{1}$ Thiago Soares ${ }^{2}$}

Recibido: 2017-10-24

Enviado a pares: 2018-01-09
Aprobado por pares: 2018-03-14

Aceptado: 2018-04-09

DOI: 10.5294/pacla.2019.22.1.7

Para citar este artículo / to reference this article / para citar este artigo Luci, S. y Soares, T. (2019). Reguetón en Cuba: censura, ostentación y grietas en las políticas mediáticas. Palabra Clave 22(1), e2217. D0I: 10.5294/pacla.2019.22.1.7

\section{Resumen}

A través de la censura de un videoclip en los sistemas de medios de comunicación cubanos, se abordan aquí las controversias evidenciadas por la presencia del reguetón en Cuba. Género musical que se ancla fuertemente en las diásporas caribeñas en los Estados Unidos, el reguetón escenifica discusiones sobre la construcción de una noción de panlatinidad transnacional, juvenil y cosmopolita, marcada por el consumo y la ostentación, que parece interrogar la singularidad de Cuba como nación socialista en América Latina. Se levanta la problemática alrededor de la performance del "hombre exitoso" que posee mansiones y autos en un país cuya economía es fuertemente mediada por el Estado, se visualizan los conflictos con otros géneros musicales cubanos y se postula que formas alternativas y no oficiales de producción y divulgación -las cuales explicitan accionamientos identitarios globales - resquebrajan políticas nacionales sobre el "ser cubano".

\section{Palabras clave (fuente: tesauro de la Unesco)}

Reguetón; latinidad; música popular; performance; Cuba.

1 orcid.org/0000-0002-7412-2129. Universidade Paulista, Brasil. simone.pereira@docente.unip.br

2 orcid.org/0000-0002-1305-4273. Universidade Federal de Pernambuco, Brasil. thiago.soares@ufpe.br 


\section{Reggaeton in Cuba: Censorship, Ostentation and Cracks in Media Policies}

\section{Abstract}

Building on the censorship of a videoclip in Cuban media systems, the controversies arising from the presence of reggaeton in Cuba are addressed in this paper. A musical genre that is strongly anchored in the Caribbean diasporas in the United States, reggaeton stages discussions on the construction of a notion of transnational, youthful and cosmopolitan Pan-Latinity, marked by consumption and ostentation, which seems to question the uniqueness of Cuba as a socialist nation in Latin America. The problem around the performance of the "successful man" who owns mansions and cars in a country whose economy is strongly mediated by the state emerges; conflicts with other Cuban musical genres are noted; and it is claimed that alternative unofficial forms of production and dissemination - which make global identity actions explicit—undermine national policies on "being Cuban."

\section{Keywords (source: Unesco Thesaurus)}

Reggaeton; latin culture; popular music; performance; Cuba. 


\section{Reggaeton em Cuba: censura, ostentação e fissuras nas políticas midiáticas}

\section{Resumo}

Através da censura de um videoclipe nos meios de comunicação cubanos, as controvérsias evidenciadas pela presença do reggaeton em Cuba são abordadas aqui. Um gênero musical fortemente ancorado nas diásporas caribenhas nos Estados Unidos, o reggaeton encena discussões sobre a construção de uma noção de panlatinalidade transnacional, juvenil e cosmopolita, marcada pelo consumo e pela ostentação, que parece questionar a singularidade de Cuba como nação socialista na América Latina. A problemática surge em torno da atuação do "homem de sucesso" que possui mansões e carros em um país cuja economia é fortemente mediada pelo Estado, são visualizados conflitos com outros gêneros musicais cubanos e postula-se que formas alternativas e não oficiais de produção e divulgação - que tornam explícitas ações identitárias globais — rompem políticas nacionais sobre o "ser cubano".

\section{Palavras-chave (fonte: tesauro da Unesco)}

Reggaeton; cultura latina; música popular; desempenho; Cuba. 
El 13 de octubre de 2015 el cantante cubano de reguetón ${ }^{3}$ Jacob Forever lanza en YouTube el videoclip de la canción La dura (Forever, 2015), en el que canta y comparte escena con su entonces esposa, la modelo Diliamne Jouve. La puesta en escena muestra los intentos de acercamiento de una pareja, en los que el personaje masculino (interpretado por el propio Jacob) ofrece una serie de regalos a la mujer, entre ellos, un automóvil, como forma de "ganar" el corazón de su amada. El tema La dura, compuesto por Osmani Espinosa, ${ }^{4}$ es una típica canción de reguetón: la letra simple sobre el deseo de un hombre por una mujer gana tesitura de doble sentido, con beats electrónicos sincopados que unen aires de reggae y de hip-hop. El título La dura puede hacer referencia tanto a que la mujer "se haga la difícil" ("La dura, la dura, la dura de amar") en los juegos de la seducción como a la excitación de la mujer durante el acto sexual ("Pero yo sé que a ti lo que te gusta / es que yo te vaya detrás / Pero yo sé que te gusta / hacerte rogar / y hacerte la dura”). ${ }^{5}$

El video desarrolla una carrera exitosa en YouTube: en diciembre de 2016, ya sumaba más de doce millones de visualizaciones en todo el mundo (el 82 \% de la audiencia provenían de los países del Caribe, América Central, América del Sur y los Estados Unidos, de acuerdo con informaciones de YouTube) y también figura entre los productos ofrecidos en los "paquetes semanales", conjuntos de archivos digitales distribuidos semanalmente en las "oficinas digitales" (equivalentes a cibercafés, infocentros o centros de comunicaciones en otros países de América Latina) o compartidos en $\mathrm{CD}, \mathrm{DVD}$, pen drives y discos rígidos en toda Cuba. Esta es la principal forma de consumo del reguetón en la isla, toda vez que, al ser una especie de

3 Rivera, Marshall y Hernandez (2009) consideran varias grafías para la palabra reguetón. Por ejemplo, reggeatón, reggeaton, regeton, entre otras. Según los autores, las diferentes formas de escritura del nombre del género parecen dar cuenta de diferentes maneras de apropiación y resignificación de esta música en los diversos contextos latinoamericanos. En este texto, se adopta la grafía reguetón con la intención de destacar la españolización de la palabra reggeatón en el contexto de Cuba.

4 También escrito como Osmany Espinosa. Compositor de canciones famosas de reguetón en Cuba, comenzó su carrera en Manzanillo como integrante del grupo de música pop Perlas y Diamantes.

5 Las referencias al doble sentido, la sexualización de los textos y la incorporación de jergas y expresiones populares de la cotidianidad forman parte de la poética del reguetón: "la dura" como el órgano genital masculino erecto, sobre todo si aislamos el título de la canción. En el éxito global Gasolina, clásico de Daddy Yankee, el término se refiere tanto a la idea de combustible sexual como de semen ("Me gusta la gasolina / dame la gasolina"). 
"género musical maldito", el reguetón (que en el contexto cubano también es llamado "cubatón") es constantemente criticado y rechazado en los órganos de prensa y blogs socialistas. ${ }^{6}$

El 14 de marzo de 2016, cinco meses después del lanzamiento del video, Osmani Espinosa expone en su página de Facebook que el videoclip La dura habría sido censurado por la televisión cubana: "Me acaban de informar que la comisión de censura de la televisión cubana nos ha censurado el clip de Jacob Forever 'La Dura”. En la misma publicación, cuestiona: “El porqué de esta censura es porque [sic] el artista le regala un carro a la mujer que ama con tal de conquistarla y eso es muy ostentoso y especulador según su criterio". En la misma publicación, ironiza la decisión del Instituto Cubano de Radio y Televisión (ICRT) de no exhibir el clip en la televisión abierta cubana. Enumeramos aquí los cinco argumentos o cuestionamientos dispuestos en Facebook, en palabras del productor:

- $\quad$ "Alguien pudiera decirle a la comisión que en el país [en Cuba] ya está aprobada la venta de carros, con precios ridículos e impagables, pero aprobados al fin", haciendo referencia al hecho de que no habría ilegalidad en regalarle un carro a alguien, en vista de que el Gobierno habría liberado la venta de automóviles, aunque a precios exorbitantes.

- "Alguien pudiera decirle a la comisión que este video, con casi ahorita 3 millones de visitas en YouTube, ya es del altísimo gusto popular y lo ha visto millones de gente [sic] en Cuba sin necesidad de una aprobación de ninguna comisión". El videoclip fue publicado en YouTube y distribuido en los "paquetes semanales", es decir, fuera de los sistemas mediáticos controlados por el Gobierno.

- $\quad$ Alguien puede explicarle a esa comisión que esa música urbana que tanto castigan e intentan censurar también pone hoy la música cubana en alto en todos los rincones del mundo, les guste o no, y que nos hace sentir orgullosos de quienes somos, como cubanos que somos". Refiriéndose con "esa música urbana que tanto castigan" al reguetón.

6 En el periódico Juventud Rebelde, la columnista Mayra García Cardentey redactó el artículo “¿Bafles sin control?”, en el que critica con vehemencia la popularización del reguetón por parte de la juventud cubana "alienada”. 
- $\quad$ "Alguien me asegura que esos moralistas que censuran el regalar un carro en una simple fantasía, como un videoclip, si en la vida real se los regalaran a ellos ¿lo aceptarían o lo rechazarían como La Dura?”. Espinosa insinúa la corrupción y el favorecimiento en la liberación de productos mediáticos por parte de gobernantes y “censores” cubanos.

- $\quad$ "Alguien les pudiera explicar que hoy, por culpa de tanta censura, apenas se ve televisión cubana y que el pueblo prefiere otros medios alternativos donde se ve y se escucha esta nueva música cubana que [es] sin censura y que incluso es más popular, escuchada y que llena plazas y reúne masas, aun sin nunca haber salido en la TVC”: una vez más, el productor endosa el poder popular y de consumo del reguetón en contra de las políticas públicas estatales.

Las críticas de Osmani Espinosa a la censura del ICRT al videoclip La dura enumeran un conjunto de tensiones resultantes de la controvertida relación del reguetón en el contexto cubano. $\mathrm{Al}$ apelar abiertamente a un estilo de vida que glorifica el consumo, los autos, las mansiones (una "estética de la ostentación” presente en géneros musicales periféricos como el funk, el brega o el kuduro); al accionar alternativas que pasan por el enfrentamiento con las políticas mediáticas restrictivas, sobre todo de la televisión y la radio en la isla socialista; y al sugerir corrupción en los sistemas de concesión de derechos a la circulación de bienes mediáticos en Cuba, esta crítica parece tratar de "negociaciones epistémicas y morales muy sutiles que ocurren entre culturas, dentro de las culturas, entre individuos y también dentro de los mismos individuos, al lidiar con la discrepancia, la ambigüedad, la discordancia y el conflicto" (Benhabid, 2002, p. 31). En su crítica, Espinosa habla a título personal (y de sus intereses conjugados con instancias productivas del reguetón en Cuba, como los estudios Forever Music, la empresa La Oficina Secreta y el sello discográfico Planet Record Cuba, los cuales administran carreras musicales y producen videoclips en el contexto cubano), pero también lo hace en nombre "de los cubanos", al reivindicar que el reguetón hace que él y sus coterráneos se sientan "orgullosos de quienes somos, cubanos que somos".

Poner en duda qué es "ser cubano" — pertenecer a una idea de Cuba no sugerida únicamente por las políticas del Estado- se configura como 
una forma de visualizar las disputas y fisuras en relación con "un proyecto de Estado nación” en el contexto latinoamericano (Martín-Barbero, 2012). Dicho de otro modo, se trata de aquella propuesta de una idea de Estado nación vinculado a un tipo de nacionalismo que conjuga políticas culturales, culturas populares, principios de lo que significa el "ser" de un determinado país y la propia naturaleza disruptiva e inacabada de la noción de identidad nacional, la cual es siempre actualizada, performada, re-escenificada y recolocada, inclusive delante del vasto arsenal mediático en circulación. Cuba representa, dentro de América Latina, un contexto aún más singular de negociación y resistencia en relación con la "latinidad". La propuesta, por tanto, de este artículo es discutir las disputas en torno al reguetón en el contexto urbano cubano a partir de un conjunto de cuestionamientos que se refieren a:

- Los flujos migratorios y mediáticos en la región del Caribe, ya que el reguetón es un género que tiene sus orígenes en el reggae y en el rap en español proveniente de las prácticas musicales que conectan Nueva York, Jamaica, Panamá y Puerto Rico, así como el contexto de movilidades del siglo XXI (de personas, de imaginarios, de cultura mediática), en el que el reguetón se convirtió en un elemento transnacional que acciona diferentes identidades ligadas a un cierto panlatinoamericanismo o una latinidad pop.

- Una trayectoria del reguetón como género musical y sus tirantes relaciones con las prácticas musicales en América Latina. Destacamos aquí el rechazo y la desvalorización del género a partir de la idea según la cual se trata de una música de contenido inapropiado, excesivamente sexualizada y desprovista de calidad artística, lo cual la desvincula — por tanto- de las políticas culturales en torno de las naciones latinoamericanas.

- Las negociaciones del reguetón en el contexto cubano, su contexto de producción que prescinde de las políticas estatales; su forma de grabación y de remuneración, que acciona la presencia de empresas privadas en Cuba, además de la forma de circulación del género musical, a través de un conjunto de prácticas digitales que involucran piratería en redes de banda ancha y consagran el formato "paquete 
semanal" como alternativa para enfrentar las políticas mediáticas de la isla a través del consumo.

- Las disputas políticas que involucran a seguidores del reguetón, las cuales provienen, por un lado, del reconocimiento del género musical como una forma de "resistir" a los constantes intentos de censura por parte de los órganos del Gobierno cubano; y por el otro, un uso estratégico de esta censura como una forma de marketing capaz de generar un posicionamiento singular para el "resistente" "cubatón" (reguetón cubano).

- Las articulaciones del reguetón con el sistema productivo de la música pop latina en Miami, las cuales evocarían — también — disputas sobre la legitimidad del género musical, dada la adhesión de cubanos exiliados en esta ciudad a la idea de que Cuba sería un país "atrasado" y "desconectado". Todo ello genera voces disonantes que usan el género musical para discutir sobre la "modernización” de la isla.

A partir del conjunto de críticas del artista cubano Osmani Espinosa a la censura del videoclip La dura, destacamos aquí tres ejes de reflexión que nos permiten hacer inferencias sobre las disputas del reguetón como mercado musical, tanto latinoamericano como cubano.

No tenemos la pretensión de construir análisis concluyentes y que expresen síntesis explicativas y totalizantes sobre el género musical del reguetón o de sus expresiones en Cuba. Solo pretendemos a través del análisis de un caso (el videoclip de una canción y sus reverberaciones) comprender sentidos y dimensiones accionados por el reguetón como expresión musi$\mathrm{cal} /$ cultural en lo que presentan respecto de ambigüedades, rasuras y fisuras frente a discursos hegemónicos (dentro y fuera del mundo académico) que lo encaran de manera dicotómica. No es nuestra preocupación un análisis global de un género musical (ya realizado por autores citados en el artículo), sino una reflexión que articula lo particular a los procesos más generales y tiene en sus bases una mirada más antropológica de interpretación de los fenómenos, en la que los fragmentos pueden ser articulados a sentidos más globales, en una dialógica entre los detalles y las macrointerpretacio- 
nes, que aquí se refieren a las migraciones y diásporas contemporáneas, así como a las lógicas del mercado de la música pop latina.

\section{Des-localizar el reguetón}

La búsqueda por la comprensión de los orígenes, las transformaciones y los circuitos sociosónicos del reguetón como género musical supone una reflexión sobre la región del Caribe (insular y continental) como lugar de encuentros, cruces y mezclas culturales y musicales multidireccionales desde hace siglos (Rivera-Servera, 2009), lo cual hizo posible el surgimiento de géneros de música mediática en el siglo XX como el bolero y la salsa, entre otros. Esta búsqueda discute también las rutas y trayectorias de las diásporas y migraciones actuales, de fuerte carácter transnacional, que, junto con los medios de comunicación electrónicos, forman parte de los procesos disyuntivos que la cultura global explicita. Estos últimos alteran los imaginarios globales y las formas de interculturalidad, al tiempo que crean nuevas esferas públicas de diáspora (Appadurai, 2004), de identificaciones, apropiaciones y mediaciones.

Ya es prácticamente una convención en la literatura sobre el reguetón tratar el género como algo originado a partir de la mezcla entre reggae, dancehall jamaiquino y rap en español, los cuales se hibridaron de forma más marcada en Panamá y Puerto Rico a lo largo de las décadas de los ochenta y los noventa, y guardaron como base rítmica de fondo el dembow, ${ }^{7}$ común a muchos estilos musicales caribeños. Si bien la presencia de inmigrantes jamaiquinos en Panamá desde la construcción de su famoso canal en la primera década del siglo XX trajo elementos de la cultura reggae y del Caribe anglófono a la música panameña, también es cierto que las migraciones de caribeños (panameños, jamaiquinos y puertorriqueños) a Nueva York tienen un papel fundacional en el origen de este género musical (Marshall, 2009).

7 Dem Bow fue una grabación exitosa hecha por el DJ y cantante Shabba Ranks, en 1991, en Jamaica. Se constituyó allí un ritmo sincopado que mezcla la percusión con la voz del DJ, transformándose en una sonoridad producida digitalmente (riddim), que se convertiría en la base rítmica para gran parte de los temas de reguetón de la actualidad. Se le conoce también como dembo e dem bow (Marshall, 2008). 
Quintero Rivera (2009) apunta en qué medida la efervescencia de la década de los setenta e inicio de la década de los ochenta en el Bronx neoyorquino - la cual dio origen a la salsa, al rap, al hip-hop y a las variaciones del jazz latino - fue fruto de las relaciones entre afroestadounidenses y latinos. Las prácticas musicales y artísticas producidas a partir de estas mezclas formaban parte de una cultura urbana periférica resistente a los espacios institucionales y domésticos, así como a sus respectivos símbolos de autoridad, statu quo y mercado. El corte étnico y de clase forjó mucho de lo que son estas expresiones musicales.

Sobre el rap y el hip-hop ya se ha discutido bastante, particularmente sobre su origen sociocultural y musical. Sin embargo, resaltamos aquí que el reguetón también tiene, en gran medida, sus orígenes en estos circuitos, contextos y prácticas musicales y culturales. A finales de la década de los ochenta, jóvenes panameños y puertorriqueños que habían regresado de la vida migrante en Nueva York comienzan a producir y grabar versiones caseras de rap en español. De las mezclas entre el rap y el reggae dancehall jamaiquino (Marshall, 2008) surge el reguetón paralelamente en Panamá y Puerto Rico, a fines de la década de los noventa. Este se edifica como género musical (en cuanto a reconocimiento del público y del mercado) en la primera década del siglo XXI, cuando hits como Gasolina, de Daddy Yankee, y Oye mi canto, de N.O.R.E., se disparan en la radio, la TV y demás espacios musicales de los Estados Unidos y en varias partes del mundo.

Antes de eso, en la segunda mitad de la década de los noventa, el género underground asociado a las periferias - el cual sufrió, inclusive, aprehensión de CD y de otras copias por parte de la policía de Puerto Rico en 1999- fue paulatinamente ganando colores más comerciales y una estética más pop, debido al trabajo de productores y DJ como Luny Tunes, DJ Nelson, DJ Playero y DJ Joe. El underground, que ya es llamado reguetón, cambia sus recursos "de samplers a sintetizadores, introduciendo el uso de beats percutidos, partes de música electrónica, arpegios oriundos del trance y efectos sonoros de dibujos animados" (Marshall, 2009, p. 52; traducción mía). En esta transición (de orientación más pop o tecno, pero que mantuvo la base rítmica de los riddims del dembow - con acentos de $3+3+2$ o 
boom-ch-boom-chick-), se fue constituyendo el reguetón. Con la destitución de algunos elementos y sentidos y la incorporación de otros, el reguetón se vuelve más bailable y "tropical" (pues, a partir de aquí, se mezcló con salsa y bachata) y alcanza éxito comercial y se convierte en un ícono de las juventudes de Puerto Rico y de otras partes del Caribe antes de "explotar" en los Estados Unidos.

Marshall (2009) analiza el reguetón y sus transformaciones desde su origen como música negra y underground hasta convertirse en "reguetón latino" (en alusión a la letra del mismo nombre que popularizó Don Omar), al tiempo que reflexiona sobre las controversias, los cambios y los des-caminos que este género toma. En la primera década del siglo XXI, el reguetón, ya con las características bailables, estéticas y comerciales que conocemos hoy, ayudó a construir y propagar una noción de identidad panlatina. Esto accionó una idea de "latinidad" que buscaba ir más allá de los elementos caribeños, afroestadounidenses o inclusive afrolatinos, englobando una categoría translocal que intentaba representar todo el subcontinente, de México a la Patagonia.

Conviene comprender un poco el contexto de las décadas de los ochenta y los noventa, cuando la propia noción de latino y latinidad se fue transformando en el imaginario estadounidense y en la construcción identitaria de los grupos latinoamericanos que vivían en los Estados Unidos. En este momento, se conjugaban por lo menos dos elementos centrales: los cambios en el capitalismo mundial global y las dimensiones culturales de la globalización, en la que los flujos globales y locales pasan a negociar sentidos y a tener - en la búsqueda de alteridad y de otras sonoridadesuna lógica que otorga valor de cambio y distinción en el mercado de bienes simbólicos a aquello que parezca exótico o "de raíz".

También cabe mencionar las migraciones transnacionales que evidenciaban la presencia de generaciones de hijos de inmigrantes oriundos

8 "Tropical” es una categoría acuñada por la industria fonográfica en la década de los cuarenta para designar la música bailable de origen caribeño. El término es usado hasta hoy de maneras diversas. No se puede perder de vista su componente exotizante, en el que lo tropical acciona nociones de naturaleza, playa, sexualidad, selva, y revela colores y aspectos de la postura colonialista frente al sur global (Negus, 2005; Pereira, 2017). 
de América Latina ya nacidos en los Estados Unidos y de nuevos migrantes que llegaban. Ambos grupos componían un gran mercado que guardaba diferencias en relación con generaciones anteriores y que podría ser explotado. La década de los noventa hizo evidentes transformaciones en las estrategias de las industrias culturales y del entretenimiento estadounidenses, que pasaron a ver en el sello "latino" actualizado un importante nicho de mercado donde invertir, algo que tendría su ápice en el llamado boom latino de finales del siglo XX y principios del siglo XXI (Pacini, 2003; Fiol-Matta, 2002).

A esto se suman los cambios generacionales y culturales protagonizados por jóvenes latinos que vivían en los Estados Unidos (y también en el Caribe), recién llegados o hijos de migrantes ya nacidos en el país. Pacini (2010) apunta que los cambios en la esfera de las migraciones transnacionales en la década de los noventa (como la presencia determinante de la comunicación mediática e internet, al igual que los flujos multidireccionales en los desplazamientos) alteraron los sentidos de identidad y pertenencia en las generaciones más jóvenes de latinos. Esto se tradujo en un importante promotor de fusiones entre musicalidades latinas y no latinas, como las mezclas de rap, reggae - y posteriormente salsa, merengue y bachata — producidas en el reguetón. Nuevos gustos musicales que - si bien no rechazaban por completo el merengue y la salsa ${ }^{9} \tan$ admirada y tan asumida por sus padres - se abrían y buscaban otros ritmos, sonidos e imaginarios correspondientes a sus identidades múltiples y mezcladas, fruto de las experiencias en contextos urbanos globales y transnacionales, las cuales se objetivaban en la búsqueda de una "latinidad" más cosmopolita.

Si los caminos de relaciones, dominaciones y mutuas influencias culturales entre los Estados Unidos y América Latina, particularmente el Caribe, tienen una historia discontinua y compleja desde el siglo XIX, en la última década del siglo $\mathrm{XX}$ estas relaciones asumieron contornos específicos. En este contexto, la industria musical estadounidense se fue preo-

9 Es importante apuntar lo mucho que la salsa de la década de los setenta se transformó en un símbolo identitario étnico-nacional para los puertorriqueños en los Estados Unidos como para los residentes en la isla. Para una discusión detallada sobre el asunto, ver Quintero Rivera (1998) y Pacini Hernandez (2010). 
cupando por comprender los gustos y el consumo musical de los migrantes latinos hispanoamericanos (cuya presencia dio un gran salto en las décadas de los ochenta y los noventa). Tales individuos consumían no solo música en español, sino también en inglés. Para un mercado acostumbrado hasta entonces a categorizar estilos y géneros en esencialismos étnicos y raciales, la nueva demografía y las mezclas y complejidades surgidas representaban desafíos y oportunidades.

El hecho de que varias sedes de industrias musicales y del entretenimiento se concentren en Miami desde finales de la década de los noventa (y ya no más en centros formadores como Los Ángeles y Nueva York) revela una creciente latinoamericanización del concepto de música latina, en palabras de Pacini (2010, p. 156), en un afán de aproximarse a los grupos latinos bilingües que allí viven y conectarse también con el público de América Latina, particularmente del Caribe, dada la estratégica posición geográfica de Miami respecto de dicha región (Negus, 2005). Una explícita globalización de las propias estructuras del mercado y de la industria de la música evidencia la centralidad de Miami como la capital cultural de América Latina (Yúdice, 2002) o centro irradiador de una estética musical miamizada (Party, 2008). La ciudad se convirtió en el centro de industrias disqueras y de entretenimiento en lo que respecta a constitución de carreras de músicos, en el sentido de hacerlas "internacionales" y obtener éxito en América Latina y el resto de los Estados Unidos, gracias a factores como la actuación de productores, cuestiones geopolíticas y costos de producción.

Fue construyéndose allí una cierta estética de pop latino (Fiol-Matta, 2002), que ayudó a construir una identidad latina globalizada y genérica, la cual se nutre de lo local-étnico para transformarlo en producto de consumo masivo. La explosión de Ricky Martin, Jennifer López o Marc Anthony guarda relaciones con este contexto de reorganización de las industrias cultural-musicales en función de los contextos de hibridismos, tensiones, negociaciones y transnacionalismos que los grupos juveniles "latinos" evidenciaban en sus vidas cotidianas, sus gustos y consumos culturales, materiales y simbólicos, construyendo nuevos sentidos de "latinidad". En estas industrias, el reguetón fue abrazado como el sonido de una generación que, 
si bien buscaba guardar y actualizar elementos de la cultura de origen, intentaba utilizarlos, no solo de manera folclórica, sino articulada a un cosmopolitismo urbano en hábitos, valores y subjetividades.

Más allá de la cuestión de mercado, la centralidad de Miami ayuda a construir sentidos de latinidad (en las identidades, en la estética musical y en su recepción) que colaboran con la comprensión generalizada de una idea de latinidad transnacional. Sin duda, se trata de una latinidad ya transformada, muchas veces pasteurizada y exótica, pero que juega con las cuestiones que la interculturalidad nos desafía a cada momento, las cuales impulsan a la acción de producción de diferencia subyacente en las experiencias identitarias. Es, además, una latinidad forjada en esferas públicas de diáspora (Appadurai, 2004), en las que las industrias de la cultura y el mercado tienen un papel hegemónico, pero donde los sujetos latinos, migrantes o no, actúan también en las negociaciones producidas en el mainstream al hacer uso y consumir símbolos, voces, ritmos y sonoridades, y darles significaciones propias. El papel de los imaginarios mediáticos - textuales, visuales y sonoros- trasciende espacios nacionales y hace que las arenas de negociación de sentidos e interculturalidad - ya en las ciudades, ya en los espacios de consumo musical - actúen en la construcción y performatividad de las identidades, las pertenencias y el cosmopolitismo que interconectan lo local con lo global.

Es en este contexto que el reguetón ha asumido un importante papel. Si la referida construcción de una panlatinidad parece estar presente en las lógicas de producción y divulgación del reguetón a partir de la primera década del siglo XXI, es necesario recordar que sus usos pueden construir sentidos otros en los diálogos con las culturas locales, a despecho de su estética que se quiere pop, global y comercial. Tales usos accionan nociones políticas de etnicidad y clase, identidades juveniles y sentidos de nación, como es posible notar de maneras diferenciadas, por ejemplo, en Puerto Rico y en Cuba. Además, los caminos recorridos por el reguetón en la actualidad revelan insurgentes formas de creatividad más allá del mainstream, las cuales se expresan en letras, fusiones sonoras y videoclips producidos en Nueva York, Miami, San Juan o Medellín y que crean diferentes senti- 
dos de localidad (Rivera-Servera, 2010). El dúo Calle 13 es, tal vez, el ejemplo más conocido de estas formas.

\section{"Está aprobada la venta de carros"}

En una mansión a orillas del mar, el cantante Jacob Forever lamenta que, a pesar de hacer de todo para conquistar el amor de una mujer, ella siempre "se hace la difícil". Una cámara dispuesta en un dron sobrevuela la mansión. En el área de la piscina, las olas del mar rompen contra el muro de la terraza. Cae la tarde. Corte. Una hilera de cajas de regalo en el piso, el personaje de Jacob toca el timbre y la referida mujer - "la dura"- ignora los presentes. Corte. La insistencia aumenta y ahora él estaciona un auto Mercedes Benz con cinta y lazo, con lo cual insinúa que se trata de un regalo para ella. Más desdén. Es en este conjunto de ofertas y compensaciones afectivo-financieras que se desarrolla el videoclip censurado La dura.

Aunque no exista un comunicado textual sobre el motivo de la censura del video, en su publicación de Facebook, Osmani Espinosa afirma que la presencia de un auto como presente sería ostentosa y ofensiva al estilo de vida cubano, con bajos salarios y con una serie de restricciones, inclusive alimentarias, debido al embargo económico impuesto por los Estados Unidos, entre otros factores político-económicos. Al ironizar que "ya está aprobada la venta de carros" en Cuba, Osmani coloca en perspectiva diferentes estilos de vivir en la isla socialista y así discute formas de lidiar con cuestiones de orden económico y político en la cotidianidad.

Acciones como comprar un auto, ofrecer regalos, cortejar a la "pretendida" con objetos de valor forman parte del imaginario de la cultura pop mundial, desde Marilyn Monroe cantando Diamonds are a girl's best friend en la película Los caballeros las prefieren rubias, hasta la lectura irónica de Madonna en el videoclip Material girl, pasando por el conjunto de videoclips de hip-hop y $R \leftrightarrow B$, con hombres viriles y ricos ofreciendo regalos a mujeres sensuales y esculturales. En el contexto cubano, sin embargo, esta premisa es problematizada, toda vez que dialoga con un conjunto de prácticas sociales y de consumo generadas a partir de la apertura del país a la iniciativa privada. El primer paso del Gobierno cubano, antes de liberar la venta 
de automóviles en la isla, fue conceder licencias de apertura de pequeños negocios a los ciudadanos. Se trata de un paso significativo en el lento proceso, en curso en 2016, que el economista Richard Feinberg (2012) denomina en su estudio The new cuban economy: What roles for foreign investments? "desburocratización" del Estado cubano. Emerge la figura del "cuentapropista", como son llamados los pequeños emprendedores cubanos, en general responsables por transporte de cargas y pasajeros, alquiler de casas, cuartos y galpones, ventas de alimentos y prestación de servicios de telecomunicaciones. Estos "cuentapropistas" poseen poder de compra, negociación y ostentación en una sociedad marcada por estratificaciones sociales relativamente estables. Los individuos exitosos, económicamente autosustentables y administradores de sus negocios, problematizan algunas líneas maestras de los indicadores de un modo de vida "revolucionario". Se abren brechas para otras vivencias, otros modos de lidiar con las injerencias del Estado, bien como en las micropolíticas de lo cotidiano.

La apertura económica del país genera impases alrededor de imaginarios construidos dentro del proyecto de la Revolución, de las lógicas sociales internas que crean asimetrías y desigualdades de clase, inclusive en una sociedad que se dice "igualitaria", y delante del contexto político favorable a las relaciones comerciales, sobre todo a partir del reinicio de las relaciones diplomáticas entre Cuba y los Estados Unidos en 2014. Parte de las canciones de reguetón, por tanto, colocan en narrativas tales impases, dan cuerpo y textura ficcional a una discusión que involucra elementos de clases sociales, género, raza y también dimensiones generacionales en Cuba (Soares, 2016a).

El hombre rico cubano sería, por tanto, un personaje profundamente problemático si pensamos en los cuadros performáticos que tales caracterizaciones escenifican (Taylor, 2009). En primer lugar, porque remite a un imaginario ampliamente criticado en el contexto de Cuba que relaciona los bienes del capitalismo con el individualismo, con la acumulación de riquezas, que llevaría al proceso de reificación de lo cotidiano y cosificación de los sujetos, más concretamente, de la mujer. Esto toca directamente ejes del proyecto socialista instaurado por la Revolución cubana en 1959. En segundo lugar, porque exponer riqueza, en este contexto, opera bajo lógicas de disputa del consumo, pero también abre fisuras en las amplias insinua- 
ciones en torno a la corrupción y el favorecimiento (citadas inclusive por Osmani en su crítica en Facebook) de figuras "de frente" del Gobierno. Finalmente, porque acciona un problemático hito performático, construido históricamente: el del cubano que dejó el país, prosperó económicamente, envía dinero para sus parientes en la isla, pero goza de la libertad y de las dádivas del capital a poco más de $200 \mathrm{~km}$ de La Habana, del otro lado del mar Caribe, en Miami.

\section{"Esta música urbana que tanto castigan"}

El productor Osmani Espinosa (2016), en su crítica a la censura del videoclip La dura por el Gobierno cubano, afirma: "Esa música urbana que tanto castigan e intentan censurar también pone hoy la música cubana en alto en todos los rincones del mundo, les guste o no, y que nos hace sentir orgullosos de quienes somos como cubanos que somos". Destacamos en este argumento la reivindicación en torno a la legitimación del reguetón ("música urbana que tanto castigan"), considerada una música de bajo valor estético y cultural, y también sobre la no nacionalización del reguetón como "música cubana”. Las disputas sobre lo que se denomina "música cubana” atraviesan problemáticas alrededor de las políticas culturales (quién define qué es la música cubana), de los circuitos productivos y de exhibición (oficiales y no oficiales), y también por el consumo y por la definición de lo que se conviene llamar "mi música".

Sin querer entrar en dinámicas esencialistas, Neustadt (2002) hace un análisis comparativo del álbum-película Buena Vista Social Club —que cristalizó en el mundo una idea de "música cubana" como aquella producida por los artistas Ibrahim Ferrer, Rubén González, Orlando "Cachaíto" López, Eliades Ochoa, Omara Portuondo y Compay Segundo-y del disco Tremendo delirio, de La charanga habanera —el álbum fonográfico más vendido en Cuba en 1996, el mismo año del lanzamiento mundial de Buena Vista Social Club - con la intención de percibir los prismas y encuadres posibles de lo que se define como "música cubana." ${ }^{10}$ La perspectiva del autor es percibir cómo la idea de "música cubana" es permeada por instancias

10 Tanto Buena Vista Social Club como Tremendo delirio fueron producidos bajo el sello EGREM (Empresa de Grabaciones y Ediciones Musicales), la grabadora oficial delEstado cubano. 
mediáticas —en este caso, la película dirigida por Wim Wenders-, no solo contraviniendo las políticas culturales del Estado cubano, sino también delante de las demandas mercadológicas y reescenificaciones de la cubanidad en los sistemas mediáticos. También está en cuestión el reconocimiento de la idea de una Cuba nostálgica de la industria del turismo mundial, en contraste con la producción de músicos contemporáneos de la isla, quienes intentan negociar con este imaginario ampliamente seductor y difundido mediáticamente y, al mismo tiempo, huir de tales estereotipos al presentar alternativas sónico-performáticas.

Lo que está en juego, en el análisis de Neustadt, es cómo la identidad cubana es performatizada tanto en Buena Vista Social Club como en Tremendo delirio: cómo se proyecta y también cómo es vista por el mundo. Es desde esta constante oscilación que las identidades culturales toman forman, se estabilizan, se transmutan y se reconfiguran. Por ello, cualquier concepto que trate de definir música e identidad nacional necesita ser circunscrito, limitado y pasible de ser reencuadrado temporal y contextualmente, en la medida en que resulta huidizo, complejo y contradictorio.

El autor sintetiza la ambivalencia de las "políticas de los ritmos cubanos” al entender que el álbum Buena Vista Social Club negocia con un género musical llamado "son", que deriva de una vinculación jazzística de la salsa y de los ritmos latinos, mientras que Tremendo delirio está ampliamente encuadrado en la timba, género de ritmo acelerado, percutido, corporal, surgido en el llamado periodo especial de la década de los noventa, muy combatido por el Estado y en la actualidad ya incentivado por órganos estatales. De esta lectura se desprenden dos visiones en disputa (inclusive valorativa) sobre lo que se llama "música cubana": una que atiende al mercado internacional por su carácter sofisticado y memorialista y otra que parece tratar sobre un mercado interno, bailable y contemporáneo. Aunque limitada por la delimitación de los álbumes (ambos grabados por la estatal EGREM [Empresa de Grabaciones y Ediciones Musicales], que no incluye artistas de reguetón en su catálogo), es posible notar que parte de estos resultados vistos por Neustadt son recombinados, con otras variables, en la 
consideración sobre el reguetón como "música cubana”. Nos interesa aquí situar históricamente el reguetón a partir de la timba, en la medida en que, de acuerdo con Nuestadt,

\begin{abstract}
la timba es relativamente poco conocida fuera de Cuba y está muy alineada a la experiencia musical de los jóvenes cubanos contemporáneos. Parte del éxito tiene que ver con la forma en que este género musical es experimentado física y socialmente en la música bailable cubana. Al mismo tiempo, las letras de la timba añaden una dimensión política a la música que contribuye tanto con su fama como con su propio aislamiento en la isla. (2002, p. 156)
\end{abstract}

La timba también ejerce una función en la socialización a través de la música que atraviesa la idea de "diversión" y "liberación"; algo controvertido y liberal que no era discutido ni presentado en los medios de comunicación cubanos en la década de los ochenta. "La timba fue uno de los más efectivos vehículos que los artistas tuvieron para hacer críticas efectivas al Gobierno en Cuba” (Neustadt, 2002, p. 156). El principio de crítica abierta al Gobierno parece seguir camuflando otras críticas al mismo Estado cubano en el reguetón; ahora más abiertamente al tratar de aspectos que se conectan al modo de vida de los cubanos exiliados. En este sentido, no es posible, por ejemplo, separar la censura del reguetón en el contexto cubano de su imaginario ligado a Miami, de una idea de música latina que "une" Cuba al resto de América Latina y que rompe, por ejemplo, con el principio de singularidad revolucionaria de la isla en el contexto latinoamericano. Lanzamos la premisa de que parte del rechazo al reguetón en Cuba también está articulado a una disputa simbólica entre La Habana y Miami, la ciudad "revolucionaria" de los que se quedaron contra la ciudad "desertora" de los que rompieron con el proyecto socialista.

\title{
Obstáculo cubano
}

Cuba es frecuentemente tratada como una especie de "mercado obstáculo” para la circulación del reguetón. Desde las propias políticas de censura de las instituciones mediáticas en la isla, pasando por el nulo atractivo del mercado consumidor cubano (fuerte presencia del Estado en la economía, bajos salarios, poco poder de compra), la isla de tradición socialista 
demanda estrategias específicas por parte de las industrias del entretenimiento. La principal dificultad está en hacer que los productos "reguetoneros" lleguen a los cubanos, toda vez que los sistemas televisivo y radiofónico cubanos obedecen las leyes del ICRT, el cual deliberó, luego de sesiones de sus comisiones parlamentarias en diciembre de 2012, que las letras consideradas vulgares y ofensivas no se transmitirían en la programación nacional. El presidente del ICRT del momento, Danilo Sirio López, declaró que "en los canales nacionales de radio y TV no se divulga contenidos groseros, banales, letras ofensivas ni videoclips que atenten o denigren la imagen de la mujer, de los cubanos y de la comunidad internacional" (Díaz, 2016). Estamos delante de un doble problema de circulación: cómo entra en el mercado cubano el reguetón producido en otros países de América Latina (agenciado ampliamente por instituciones estadounidenses) y cómo el propio reguetón cubano delinea, también, sus lógicas de consumo entre los jóvenes de la isla socialista.

Entran en escena las estrategias vinculadas con la producción de los "paquetes semanales", conjunto de archivos digitales reunidos en computadores y "descargados" en pen drive o discos rígidos de cubanos al precio de CUC 1, el equivalente a poco menos de USD 1. Los "paquetes" reúnen archivos con revistas en PDF, impresiones de sitios web prohibidos, fotografías, videoclips, software, fotografías, aplicaciones para teléfonos celulares y, naturalmente, archivos de audio. No está disponible en el país, al menos para residencias particulares, la televisión por cable e internet. Las antenas parabólicas también son prohibidas y se necesita autorización estatal para instalarlas. En 2016, la televisión cubana consistía en seis canales de televisión abierta, ${ }^{11}$ cuya programación es controlada por el Gobierno, a excepción de dos canales internacionales. Se exhiben, mayormente, programas de entretenimiento, culturales, educativos, transmisiones de sesiones políticas y eventos deportivos. También hay espacio para películas, series $\mathrm{y}$ telenovelas cubanas o internacionales (sobre todo brasileñas y colombianas). Una orden en el país solo permite atracciones del exterior cuando son adquiridas y aprobadas por el Gobierno. Parte de la construcción de

11 Son los canales Cubavisión, Canal Habana, Canal Educativo, Canal Educativo 2, Multivisión y Tele Rebelde. 
"remiendos" mediáticos en Cuba, que culminan con la elaboración de los "paquetes semanales", tiene su origen en el pirateo de señales de TV a través miles de antenas parabólicas y de otros tipos, clandestinas, venidas de los Estados Unidos. Desde 2005 se estima que al menos el $10 \%$ de la población cubana ha tenido acceso a películas, novelas, series y programas deportivos producidos en el exterior a través de la piratería. Los dueños de las antenas conectan sus televisores a las de los vecinos, quienes, a su vez, distribuyen el acceso. Este servicio clandestino puede costar USD 10 mensuales.

Más barata que el servicio de "suscripción" de TV clandestina y un poco menos ilegal es la compra de los "paquetes semanales". Se presume que estos surgieron entre 2008 y 2009 con el incremento de la red de banda ancha por parte del Estado, antes restringida a funciones militares, educativas y de salud. La liberación de internet para redes hoteleras y turísticas puede haber abierto "flancos" en la censura para el consumo de contenidos digitales en la isla. Gracias a los “paquetes”, es posible tener acceso — con una semana de retraso - a lo que transmiten las televisiones extranjeras junto con contenido bajado de internet, e incluye también publicidad. Se delinean, entonces, dos hipótesis sobre la elaboración de los "paquetes semanales": la primera, que los videos pueden ser bajados en las instituciones estatales donde hay banda ancha disponible (como hospitales, ambientes militares, universidades y escuelas), o la segunda, a través del pirateo de las redes digitales, montando "remiendos" para el uso privado de las redes disponibles en estos locales. Esto último incluye también la comercialización de internet por mediadores, algo terminantemente prohibido por el Gobierno.

La elaboración de los "paquetes" pasa por la relación entre cubanos exiliados en Miami y los habitantes de la isla. 'Se especula que los 'paquetes' son armados en Miami, reenviados digitalmente a 'oficinas digitales' en ciudades cubanas, donde se les añaden anuncios publicitarios de peluquerías cubanas, casas de hospedaje, estudios fotográficos y nuevos negocios privados en la isla" (Rodríguez, 2014, p. 1). Llamado informalmente "YouTube cubano" (Rodríguez, 2014), los "paquetes semanales" emplean un número significativo de cubanos habitantes de grandes ciudades que se dedican a comercializarlos. Estas personas van a otras ciudades del interior, con un 
acceso a internet todavía más bajo, y también operan dentro de las grandes ciudades mediante una red de "paqueteros" que distribuyen los contenidos de varias maneras. La forma "oficial" es tener un local fijo bajo una licencia de "vendedor/comprador de discos". El Estado — se presume — se hace de la vista gorda en relación con el contenido que venden estos locales. En las calles, también "vuelan” estos contenidos a través de pen drives.

Es, por tanto, a través de la red de los "paquetes digitales" que el reguetón es ampliamente oído y diseminado en la isla socialista, contrariando al Gobierno y lejos de la censura de las emisoras de televisión estatales. El caso del videoclip La dura, de Jacob Forever, es uno más de los innumerables contenidos que son censurados por los órganos públicos gubernamentales, pero que llegan al público a través de redes sociales o mediante el consumo des-intermediado de bienes culturales a través de lo que denominamos aquí "remiendos mediáticos".

\section{Consideraciones finales}

$\mathrm{Al}$ accionar la singularidad de la presencia del reguetón en el contexto cubano, intentamos no pensar en una metanarrativa oficial y lineal sobre este género musical, sino abrir la posibilidad de estudiar y contar otras contranarrativas como aquellas que analizan usos de la música y de lo que los oyentes cuentan sobre ellas. En este sentido, la noción de diáspora, de acuerdo con el concepto de Hall (2003), nos resulta útil, toda vez que trae una idea de diferencia cultural que escapa de los binarismos que separan el nos(otros) de los otros, al tiempo que destaca los espacios in between (para usar el término de Homi Bhabha), en los que los sentidos y las identidades son posicionales, inestables y relacionales. De esta forma, los procesos diaspóricos caribeños como los que presentamos aquí revelan hibridismos intermediados por luchas culturales, relaciones de poder y posibilidades de negociación. En ellos África se hace presente de diferentes formas, más residuales o emergentes, lo cual reafirma estereotipos y los subvierte en una compleja trama. El reguetón se inserta en este amplio debate en la medida en que parece resquebrajar narrativas hegemónicas de nación y de identidad latina tradicional, al tiempo que produce también fisuras en el propio mainstream musical. 
Como otros géneros musicales existentes en América Latina (cumbia villera, funk y tantos otros), el reguetón es criticado por instituciones (medios de comunicación hegemónicos, escuela, Estado, academia) por su baja calidad musical y lírica y por su componente comercial. Se argumenta que sus letras son vulgares, violentas, egocéntricas, machistas; su sonoridad repetitiva y alienante y - por tanto - "corruptora de las mentes" y sexualidades juveniles. Vale recordar que, así como en Cuba (no de forma abierta, pero sutilmente en las acciones gubernamentales), en Puerto Rico, país en el que el reguetón tuvo y tiene gran éxito, este género llegó a ser oficialmente prohibido en 2002 y luego fue incorporado como "música nacional", en disputa con la salsa de la década de los setenta, ${ }^{12}$ luego de la proyección global que tuvo Gasolina (Negrón-Muntaner y Rivera, 2007; Rivera-Riveau, 2015). Estas objeciones al reguetón conducen a una crítica y a un cuestionamiento de su autenticidad (Rivera-Servera, 2009) en relación con el rap y hip-hop, los cuales son vistos, o bien como poseedores de una tradición negra de "gueto", o bien como de letras de mayor y mejor contenido.

Es posible notar, inclusive, una desvalorización del reguetón debido a su componente corporal y bailable. La danza asociada al género y practicada por los jóvenes desde las décadas de los ochenta y los noventa tanto en el reggae dancehall jamaiquino como en el rap en español y - fuertementeen el reguetón es el "perreo" (también llamado doggy-style dance), de fuerte connotación sensual y sexual. Más todavía, la dualidad cartesiana entre cuerpo y mente, tan arraigada en el pensamiento occidental moderno, se refiere a la consciencia y a la racionalidad de manera valorativa y preferible a los estados en los que el cuerpo y la naturaleza (descalificados) se presentan.

Canciones que evocan las décadas de los ochenta y los noventa y la crítica social, con letras comprometidas con los cambios del statu quo, en

12 Infelizmente, en el espacio de este artículo, no es posible un análisis más detenido sobre el reguetón en Puerto Rico, en el que pesen los embates y las negociaciones generados en aquel contexto. Estas últimas articulan elementos de la cultura boricua en más de un siglo de protectorado de los Estados Unidos y accionan tradiciones, cosmopolitismos y cultura pop, así como nociones de nacionalismo que involucran la salsa en la isla y en los contextos diaspóricos. También hay nociones étnicas de negritud, explicitadas en el trabajo de Tego Calderón, por ejemplo, que resaltan los orígenes del género entre las sonoridades afropuertorriqueñas como la plena y la bomba (Rivera-Riveau, 2015; Negrón-Muntaner y Rivera, 2007; Quintero Rivera, 2009). 
general, son vistas en los medios académicos y otras instituciones como buenas y positivas, lo cual evidencia un logocentrismo iluminista que muestra su corte étnico y clasista distintivo y que ignora cosmogonías diversificadas que muchas músicas "mulatas" presentan (Quintero Rivera, 2009). Al hacer hincapié en la danza y el elemento corporal, el reguetón acaba chocando con estas cuestiones, no sin accionar también fuertes cuestionamientos que apuntan hacia lo mucho que en los cuerpos, en su estetización y subjetividad, están presentes sentidos políticos que irrumpen en formas de bailar y "perrear", opositoras o cuestionadoras en algunos contextos. Como ya ha argumentado Quintero Rivera (1998, 2009), la danza y los usos del cuerpo pueden contener elementos disruptivos e inclusive subversivos que disparan otro ethos diferente del ligado a la racionalidad, al trabajo y a otras normativas e ideologías prescritas. Las narrativas corporales del reguetón parecen tener mucho más para contarnos sobre las posibilidades del cuerpo, de la danza y del placer si se pueden ubicar como lugares de experimentación, de vivencia de subjetividades e identidades otras y de creación de complejos significados (Baker, 2009).

\section{Referencias}

Appadurai, A. (2004). Dimensões culturais da globalização. Lisboa, Portugal: Teorema.

Baker, G. (2009). The politics of dancing: Reggaetón and rap in Havana, Cuba. En R. Z. Rivera, W. Marshall y D. Pacini Hernandez (Eds.), Reggaeton (pp. 165-199). Durham, EE. UU.: Duke University Press.

Benhabid, S. (2002). The claims of culture: Equality and diversity in the global era. Nueva Jersey, EE. UU.: Princeton University Press.

Díaz Blanco, L. (2016, marzo 15). La censura del ICRT toca ahora a Jacob Forever. Martí Noticias. Recuperado de https://www.martinoticias.com/a/jacob-forever-censurado-cuba/117338.html 
Espinosa, O. (2016, marzo 14). Amigos míos y gente que nos siguen, me acaban de informar que la comisión de censura de la televisión cubana nos ha censurado el clip de JACOB FOREVER Yosdany Jacob Carmenates LA DURA ... [Facebook, entrada]. Recuperado de https://www.facebook.com/osmany.espinosamorales/ posts/1309005395792813

Feinberg, R. E. (2012). The new cuban economy: What roles for foreign investments? Washington, D. C., EE. UU.: Latin America Institute for Brooking.

Fiol-Matta, L. (2002). Pop latinidad: Puerto Ricans in the latin explosion, 1999. Centro Journal, 14(1), 26-51. Recuperado de http://www. redalyc.org/articulo.oa?id=37711290002

Forever, J. (2015, octubre 23). La dura [Video]. Recuperado de https:// www.youtube.com/watch?v=iMow7JqblH0

García Canclini, N. (2008). Latino-americanos à procura de um lugar neste século. São Paulo, Brasil: Iluminuras.

García Cardentey, M. (2014, agosto 14). ¿Bafles sin control? Juventud Rebelde. Recuperado de http://www.juventudrebelde.cu/opinion/2014-08-14/bafles-sin-control

Hall, S. (2003). Pensando a diáspora (Reflexões sobre a terra no exterior). En L. Sovik (Ed.), Da diáspora: identidades e mediações culturais (pp. 25- 48). Belo Horizonte, Brasil: Editora UFMG.

Marshall, W. (2008). Dem Bow, Dembow, Dembo: Translation and Transnation in Reggaeton. Recuperado de https://pdfs.semanticscholar.or g/07af/0d8ab6ae7a6ae9cec0a921b0523125aab843.pdf

Marshall, W. (2009). Musica negra to reggaetón latino: The cultural politics of nation, migration, and commercialization. En R. Z. Rivera, 
W. Marshall y D. Pacini Hernandez (eds.), Reggaeton (pp. 19-76). Durham, EE. UU.: Duke University Press.

Martín-Barbero, J. (2012). Dos Meios às Mediações. Río de Janeiro, Brasil: Editora UFMG.

Negrón-Muntaner,F.y Rivera, R.Z.(2007).Reggaetonnation.NACLAReporton the Americas, 40(6),35-39.DOI: 10.1080/10714839.2007.11725387

Negus, K. (2005). Géneros musicales y la cultura de las multinacionales. Barcelona, España: Paidós.

Neustadt, R. (2002). Buena Vista Social Club versus La Charanga Habanera: The Politics of Cuban Rhythm. Journal of Popular Music Studies, 14(2), 139-162.DOI: 10.1111/j.1533-1598.2002.tb00041.x

Pacini Hernandez, D. (2003). Amalgamating musics: Popular music ans cultural hybridity in the Americas. En F. R. Aparicio y C. F. Jáquez (Eds.), Musical migrations. Vol. 1: Transnacionalism and cultural hybridity in Latin/o America (pp. 13-32). Nueva York, EE. UU.: Palgrave Macmillan.

Pacini Hernandez, D. (2010). Oye como va! Hybridity and identity in Latino popular music. Philadelphia, EE. UU.: Temple University Press.

Party, D. (2008). The miamization of Latin-American pop music. En I. Corona y A. L. Madrid (Eds.), Postnational musical identities: Cultural production, distribution, and consumption in a globalized scenario (pp. 65-80). Lanham, EE. UU.: Lexington Books.

Pereira, S. L. (2017). Que latino? Juventudes, música e dinâmicas históricas nas relações Brasil e América Latina hispânica. En J. M. Valenzuela y S. Borelli (Eds.), Juventudes en América Latina: políticas, culturas y comunicación. Buenos Aires, Argentina: Consejo Latinoamericano de Ciencias Sociales. 
Quintero Rivera, Á. G. (1998). Salsa, sabor y control: sociología de la música tropical. Ciudad de México, México: Siglo XXI.

Quintero Rivera, Á. G. (2009). Cuerpo y cultura: las músicas mulatas y la subversión del baile. Madrid, España: Iberoamericana.

Ranks, S. (2010, junio 12).Dem Bow [Video]. Recuperado de https://www. youtube.com/watch?v=VQqwea $8 \mathrm{ZSbk}$

Rivera, R. Z., Marshall, W. y Hernandez, D. P. (Eds.) (2009). Reggaeton. Durham, EE. UU.: Duke University Press.

Rivera, R. Z., Marshall, W. y Hernandez, D. P. (2011). Os Circuitos Sociossônicos do Reggeatón. En M. Herschmann (Ed.). Nas Bordas e Fora do Mainstream Musical: Novas Tendências da Música Independente no Início do Século XXI (pp. 125-141). São Paulo, Brasil: Estação das Letras e Cores.

Rivera-Riveau, P. (2015). Remixing Reggaetón: The cultural politics of race in Puerto Rico. Durham, EE. UU.: Duke University Press.

Rivera-Servera, R. H. (2009). Musical trans(actions): Intersections in reggaetón trans. Revista Transcultural de Música, 13, 1-13. Recuperado de http://www.redalyc.org/articulo.oa?id=82220946014

Soares, T. (2016a). Acionamentos geopolíticos num show de música pop em Cuba. Galáxia: Revista do Programa de Pós-Graduação em Comunicação e Semiótica, 33, 171-183. DOI: 10.1590/198225542016227466-72190

Soares, T. (2016b). Lady Gaga em Cuba. En E. Jesus, E. Trindade, J. S. Janotti Júnior y M. A. Roxo da Silva (Eds.), Reinvenção comunicacional da política: Modos de habitar e desabitar o século XXI (pp. 85-96). Salvador, Brasil: Edufba. 
Rodríguez, A. (2014, octubre 9). Cómo hacen los cubanos para tener acceso a la TV internacional. BBC. Recuperado de http://www.bbc. com/mundo/blogs/2014/10/141009_voces_desde_cuba_alejandro_rodriguez_paquete_semanal

Taylor, D. (2013). O arquivo e o repertório: performance e memória cultural nas Américas. Belo Horizonte, España: Editora da UFMG.

Yúdice, G. (2002). El recurso de la cultura: usos de la cultura en la era global. Barcelona, España: Gedisa. 